\title{
THE ELECTROCARDIOGRAM IN NORMAL CHILDREN AND IN CHILDREN WITH RIGHT VENTRICULAR HYPERTROPHY
}

\author{
BY \\ J. F. GOODWIN \\ From the Sheffield Royal Infirmary, Dept. of Therapeutics, University of Sheffield, and the Department of Medicine \\ Postgraduate Medical School of London \\ Received June 14, 1951 \\ The need for accurate diagnosis in congenital heart disease has greatly increased the importance \\ of the various types of electrocardiogram found in right ventricular hypertrophy. This is particu- \\ larly important in children in whom the normal patterns may closely simulate those of right \\ ventricular hypertrophy. Recently the appearances in infants and children have been analysed by \\ Switzer and Besoan (1950) and by Schaffer (1950). The electrocardiogram of right ventricular \\ hypertrophy has been extensively studied by Wilson et al. (1947), by Myers et al. (1948, 1950), \\ by Goldberger (1944), by Sokolow and Lyon (1949) and by Sokolow and Edgar (1950). Sokolow \\ and Lyon included 24 children of five years of age or less in a series of 60 patients with right \\ ventricular hypertrophy.
}

\section{Present Series}

In order to evaluate the various patterns of right ventricular hypertrophy in children, two groups of cases were studied; 53 healthy children ranging from 16 months to 15 years of age, and 36 children with presumed right ventricular hypertrophy ranging from 3 to 14 years of age. All the latter cases were suffering from congenital heart disease and showed clinical and radiological evidence of right ventricular hypertrophy, and in $26(72 \%)$ cardiac catheterization or angiocardiography revealed increased right ventricular pressure or enlargement of the right ventricle respectively. Right ventricular hypertrophy was found in each of three patients who came to necropsy.

Methods. In the control group of normal children the cardiograms were taken with a Sanborn direct writing visocardiette, using standard bipolar limb leads, unipolar præcordial leads V1-6, and augmented limb leads aVR, aVL, and aVF (Goldberger, 1947). All tracings were taken with the subjects in the supine position.

In the series with right ventricular hypertrophy, three different instruments were employed; a Sanborn photographic portable machine, a Victor photographic machine, and the Sanborn direct writing visocardiette. The same standardization $(1 \mathrm{mv} .=1 \mathrm{~cm}$.) was used and the same leads were reçorded, except that in some cases the præcordial leads were limited to V1, V3, and V5. In 13 $(30 \%)$ complete chest exploration using leads V8R to V8 was performed.

The following points were studied.

(1) The pattern of the ventricular complex in leads aVR, V1, and V5.

(2) The ventricular activation time in these leads. This was measured from the onset of the QRS complex to the beginning of the intrinsicoid deflection (Sokolow and Lyon, 1949; Myers et al., 1948).

(3) The $Q / R$ or $R / S$ ratios in aVR and the $R / S$ ratio in $V 1$ and $V 5$.

(4) The ratio $R / S$ in V5 divided by the ratio R/S in V1 (Sokolow and Lyon, 1949). 
(5) The direction of the præcordial $\mathrm{T}$ waves.

(6) The position of the heart.

It was found that in both normal and abnormal cases the amplitude of individual components of the ventricular complex varied more with respiration than did the ratios, and therefore no absolute measurements of QRS amplitudes are given.

The cases were divided into four age groups: Group I, 16 months to 4 years, Group II, 5 years to 8 years, Group III, 9 to 12 years, Group IV, 13 to 15 years.

\section{Results: Children with Normal Hearts}

The findings obtained in the normal and abnormal series are outlined separately and compared and contrasted according to age in Tables I to IV. Among those with normal hearts, there were 9 subjects each in Groups I and II, 19 in Group III, and 16 in Group IV.

The position of the heart was intermediate in 29 , vertical in 21 , and horizontal in 3 children. The last position was seen in one child each in Groups I, III, IV, and the highest incidence of the intermediate position occurred in Groups III and IV.

Lead aVR. Four types of ventricular complex were seen in this lead: RS (21 subjects), QR (20 subjects), RSR' (8), and QS (4). Age did not influence the type of complex (Fig. 1, 2, 4, 5, and 6).

In all 20 children with a $Q R$ pattern the $Q / R$ ratio was greater than one, varying from a maximum of 18 to a minimum of $1 \cdot 3$. There was a tendency for the group average ratio to vary inversely with age, the highest $(8 \cdot 5)$ occurring in Group I and the lowest $(4 \cdot 1)$ in Group IV. In all children with an RS pattern the R/S ratio was less than one, varying from 0.16 (Group II) to 0.5 (Group II), and $R^{\prime} / S$ ratios varied from 0.09 to 0.16 (Tables $I$ and II).

TABLE I

Q/R Ratios IN LEAD AVR

\begin{tabular}{|c|c|c|c|c|c|c|c|c|c|c|c|c|}
\hline \multicolumn{5}{|c|}{ Normals: all 20 cases with $Q / R>1$} & \multicolumn{4}{|c|}{$\begin{array}{l}\text { R.V. Hypertrophy: } \\
3 \text { of } 32^{*} \text { cases with } Q / R>1\end{array}$} & \multicolumn{4}{|c|}{$\begin{array}{l}\text { R.V. Hypertrophy: } \\
27 \text { of } 32^{*} \text { cases } Q / R<1\end{array}$} \\
\hline & \multirow{2}{*}{$\begin{array}{l}\text { No.of } \\
\text { Cases }\end{array}$} & \multicolumn{3}{|c|}{ Q/R Ratio } & \multirow{2}{*}{$\begin{array}{l}\text { No. of } \\
\text { Cases }\end{array}$} & \multicolumn{3}{|c|}{$Q / R$ ratio } & \multirow{2}{*}{$\begin{array}{l}\text { No.of } \\
\text { Cases }\end{array}$} & \multicolumn{3}{|c|}{$Q / R$ ratio } \\
\hline & & Max. & Min. & Ave. & & Max. & Min. & Ave. & & Max. & Min. & Ave. \\
\hline Group I .. & 4 & 18 & 4 & $8 \cdot 5$ & 0 & - & - & - & 5 & 0.38 & 0.03 & 0.24 \\
\hline Group II & 5 & 14 & 1.6 & 5 & 1 & - & - & $3 \cdot 7$ & 12 & 0.75 & 0.05 & 0.3 \\
\hline Group III & 7 & 10 & $1 \cdot 3$ & $4 \cdot 7$ & 2 & $4 \cdot 5$ & 1.6 & 3.5 & 6 & 0.6 & $0 \cdot 16$ & 0.34 \\
\hline Group IV .. & 4 & $5 \cdot 5$ & $1 \cdot 3$ & $4 \cdot 1$ & 0 & - & - & - & 4 & 0.7 & $0 \cdot 13$ & 0.4 \\
\hline
\end{tabular}

* In the remaining 2 cases $Q / R=1$

The ventricular activation time lay between 0.04 and $0.05 \mathrm{sec}$. in subjects with a $\mathrm{QR}$ pattern, between 0.02 and $0.06 \mathrm{sec}$. in those with RSR', and did not exceed $0.02 \mathrm{sec}$. when an RS was present.

Lead V1. The R/S ratio was less than one in 42 children $(79 \%)$, the maximum being 0.8 and the minimum 0.08 (Fig. 1). The ratio was equal to one in 3 instances ( 1 in Group II and 2 in Group III (Fig. 6)), and was greater than one in 8 children (5 in Group I and 3 in Group II (Fig. 2 and 4)), when it varied from 7 to $1 \cdot 2$. The higher ratios were found in Group I (average 3.2), and the average in Group II was 1.4. Eleven subjects showed slurring of the QRS which in two was related to respiration (Fig. 3), and in one an RSR' pattern occurred (Fig. 5).

The ventricular activation time did not exceed 0.03 sec. except in the child with an RSR' pattern (Fig. 5 and Table III). 
TABLE II

R/S RATIOS IN LEAD AVR

\begin{tabular}{cc|c|c|c|c}
\hline & & \multirow{2}{*}{$\begin{array}{c}\text { No. of } \\
\text { Cases }\end{array}$} & \multicolumn{3}{|c}{ R/S ratio } \\
\cline { 3 - 6 } & & & Max. & Min. & Ave. \\
\hline Group I &.. & 4 & 0.18 & 0.13 & 0.17 \\
\hline Group II &.. & 4 & 0.16 & 0.07 & 0.12 \\
\hline Group III &.. & 7 & 0.2 & 0.05 & 0.12 \\
\hline Group IV &.. & 6 & 0.14 & 0.07 & 0.11 \\
\hline
\end{tabular}

* These were all normal children: in those with right ventricular hypertrophy there was a $Q / R$ ratio (see Table I).

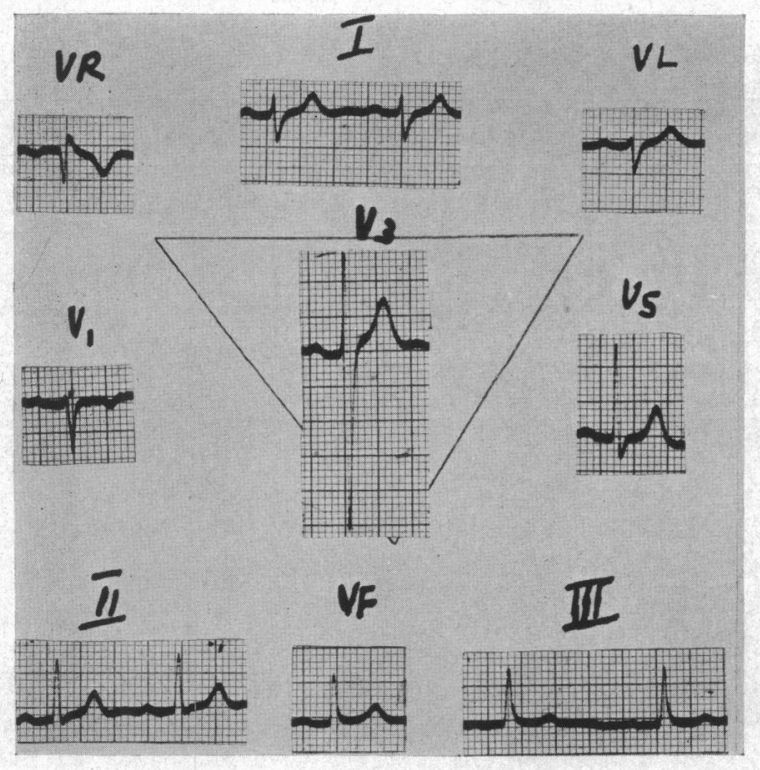

Fig. 1.- Normal heart from patient, aged 14 years. Right axis deviation. Vertical heart. $Q r$ in aVR, $r S$ in V1. T wave inverted in V1.

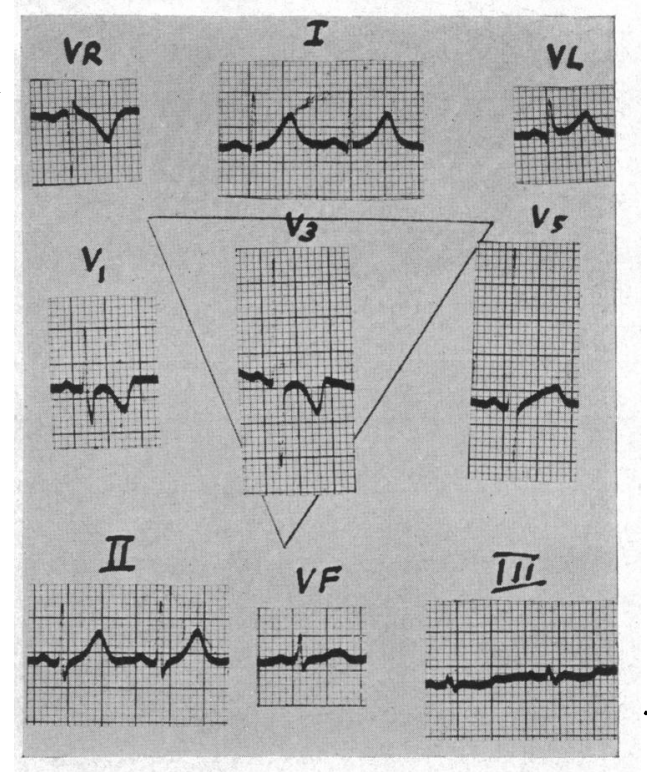

FIG. 2.-Normal heart from patient, aged 3 years. Qr in aVR, Rs in V1. T wave inverted in V1 and 3.

Lead V5. The $\mathrm{R} / \mathrm{S}$ ratio was greater than one in 52 children, varying from 40 to 2 , and there was a tendency for the group average ratios to increase directly with age. In one child (in Group III) the ratio was $0 \cdot 42$.

The ventricular activation time lay between 0.02 and $0.04 \mathrm{sec}$, and in the solitary child in whom the $R / S$ ratio was less than one it was $0.03 \mathrm{sec}$.

The ratio $R / S$ in $V 5$ divided by the ratio $R / S$ in $V 1$ was calculated and the maximum was 158 and the minimum 1.4. The averages for each group were: Group I, 11; II, 7; III, 25; IV, 30.

The $T$ waves. This was inverted in aVR in every case, and upright in aVL and aVF with the exception of 2 subjects, in one of whom it was flat in aVL and in the other inverted in aVF. In lead V1 it was inverted in 39 of the 53 subjects; $9(100 \%)$ in Group I, $8(89 \%)$ in II, $15(78 \%)$ in III, and 7 (44\%) in IV. T wave inversion was present in V2 in 19 instances, in V3 in 13, in V4 in 5, 
TABLE III

R/S Ratios and Ventricular Activation Time in Lead V1

\begin{tabular}{|c|c|c|c|c|c|c|c|c|c|c|c|c|c|}
\hline \multirow{2}{*}{$\begin{array}{l}\text { No. of } \\
\text { Cases }\end{array}$} & \multicolumn{3}{|c|}{$R / S$ ratio } & \multicolumn{3}{|c|}{$\begin{array}{l}\text { Ventricular } \\
\text { activation } \\
\text { time/secs. }\end{array}$} & \multirow{2}{*}{$\begin{array}{l}\text { No. of } \\
\text { Cases }\end{array}$} & \multicolumn{3}{|c|}{$\mathbf{R} / \mathbf{S}$ ratio } & \multicolumn{3}{|c|}{$\begin{array}{l}\text { Ventricular } \\
\text { activation } \\
\text { time/secs. }\end{array}$} \\
\hline & Max. & Min. & Ave. & Max. & Min. & Ave. & & Max. & Min. & Ave. & Max. & Min. & Ave. \\
\hline
\end{tabular}

\begin{tabular}{c|c|c|c|c|c|c|c|c|c|c|c|c|c|c}
\hline & \multicolumn{8}{c|}{ R/S ratio less than 1 } \\
\hline Group I & 4 & 0.7 & 0.25 & 0.46 & 0.02 & 0.01 & 0.016 & 0 & - & - & - & - & - & - \\
\hline Group II & 5 & 0.7 & 0.4 & 0.54 & 0.02 & 0.01 & 0.016 & 3 & 0.85 & 0.08 & 0.49 & 0.02 & 0.01 & 0.015 \\
\hline Group III & 17 & 0.8 & 0.12 & 0.39 & 0.03 & 0.01 & 0.017 & 1 & - & - & 0.25 & - & - & 0.02 \\
\hline Group IV & 16 & 0.9 & 0.08 & 0.36 & 0.05 & 0.01 & 0.02 & 1 & - & - & 0.7 & - & - & 0.02 \\
\hline
\end{tabular}

t.

$R / S$ ratio greater than 1

\begin{tabular}{l|c|c|c|c|c|c|c|c|c|c|c|c|c|c}
\hline & \multicolumn{7}{c|}{ Normals (8 cases) } & \multicolumn{5}{c}{ Right Ventricular Hypertrophy (29 cases) } \\
\hline Group I & 5 & 7 & 1.5 & 3.2 & 0.02 & 0.02 & 0.02 & $4(+3)$ & 40 & 4 & 14.2 & 0.06 & 0.04 & 0.036 \\
\hline Goup II & 3 & 1.5 & 1.2 & 1.4 & 0.02 & 0.02 & 0.02 & $3(+6)$ & 9 & 4.4 & 5.5 & 0.06 & 0.02 & 0.043 \\
\hline Group III & 0 & - & - & - & - & - & - & $6(+3)$ & 8.6 & 1.5 & 4.0 & 0.08 & 0.04 & 0.045 \\
\hline Group IV & 0 & - & - & - & - & - & - & $1(+3)$ & - & - & 3.3 & 0.06 & 0.04 & 0.05 \\
\hline
\end{tabular}

Figures in brackets represent Nos. of cases in which amplitude of deflection could not be measured.

There were 5 cases where the R/S ratio was equal to one. The ventricular activation time was $0.02 \mathrm{sec}$. in all the 3 normals, and 0.02 and $0.03 \mathrm{sec}$. in the 2 cases with right ventricular hypertrophy.

in V5 in 1, and never in V6. Except in V1, age did not influence the direction of the T waves: the lone example of inversion in V5 was from Group II (Fig. 6).

\section{Children with Right Ventricular Hypertrophy}

There were 6 cases in Group I, 15 in Group II, 10 in Group III, and 5 in Group IV. The position of the heart was vertical in 32 cases and intermediate in 4 , the ages of the latter being, 12, 12,13 , and 4 years respectively.

Lead aVR. Three types of ventricular complex were seen: QR (32 patients), RSR' (3), and monophasic $R$ (1). As in the normal series, age did not influence the type of complex.

The $Q / R$ ratio was greater than one in only 3 cases that had a $Q R$ complex ( 1 in Group II and 2 in Group III) and ranged from 1.6 to 4.5 (Fig. 7) and was equal to one in 2 cases (Groups I and III). It was less than one in 27 (72\% of all abnormal cases); the ratios varied between 0.75 and 0.03 , and the group average ratios increased with age, being 0.24 in Group I and 0.4 in Group IV. Of the 3 cases with an RSR' pattern 2 were in Group II and 1 in Group III, the average R/S ratio of the former being 0.51 , and the ratio of the latter 1.4 . The lone example of a monophasic $R$ wave occurred in Group IV and was $13 \mathrm{~mm}$. in height (Tables I and II).

The ventricular activation time lay between $0.03 \mathrm{sec}$. and $0.08 \mathrm{sec}$. (average 0.04 ) in cases with a $Q / R$ ratio of less than one, and between 0.06 and $0.08 \mathrm{sec}$. (average 0.05 ) in those with a $Q / R$ ratio 


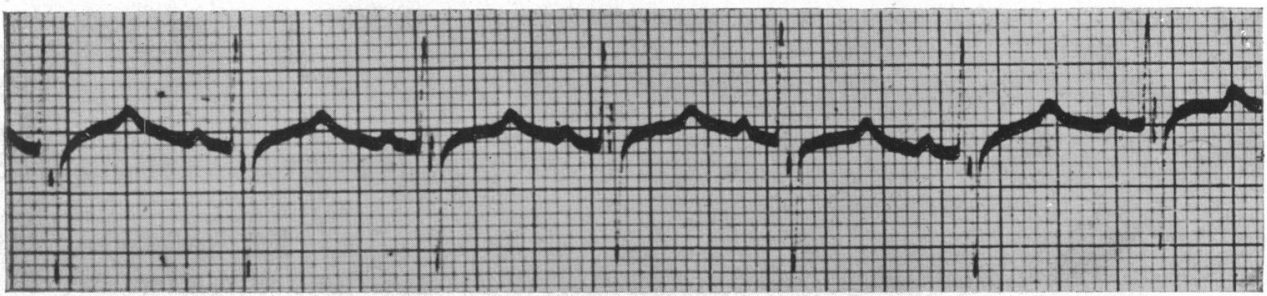

Fig. 3.-Normal heart, aged 11 years. V1 showing notching of QRS varying with respiration.

greater than one. In two cases in which this ratio was equal to one, the times were 0.04 and 0.08 seconds respectively, and in those with an RSR' pattern they did not exceed $0.08 \mathrm{sec}$. In the instance where a monophasic $R$ wave occurred the activation time was $0.03 \mathrm{sec}$. Although the maximum activation times were greater than in the normal children, the group average times fell within the same range as the abnormal cases. In none of the former subjects did a time of more than $0.06 \mathrm{sec}$. occur, however.

Lead VI. The R/S ratio was greater than one (range 40 to 1.5 ) in 29 cases $(80 \%)$, and equalled one in 2 cases which were in Groups I and II respectively. In 5 children the ratio was less than one (range 0.85 to 0.08 ), 3 being in Group I, and 1 each in Groups III and IV respectively. In 15 cases the complex consisted of a monophasic $\mathrm{R}$ wave, in 3 the voltage was too high to permit recording of amplitudes, and in 2 others the $R$ wave was preceded by a small q wave (Fig. 7 to 11 ).

In the 29 cases with $R / S$ ratios greater than one the ventricular activation time was $0.08 \mathrm{sec}$. in 2 cases, 0.06 in 3,0.05 in 2, 0.04 in 17, 0.03 in 2, 0.02 in only 1 , and could not be measured in 2 cases. Where the ratio was equal to one, the activation times were 0.03 and $0.02 \mathrm{sec}$. respectively, and where it was less than one they were $0.02 \mathrm{sec}$. in 4 cases and $0.01 \mathrm{sec}$. in 1 case (Table III).

In right ventricular hypertrophy the ventricular activation time was greater than $0.02 \mathrm{sec}$. when

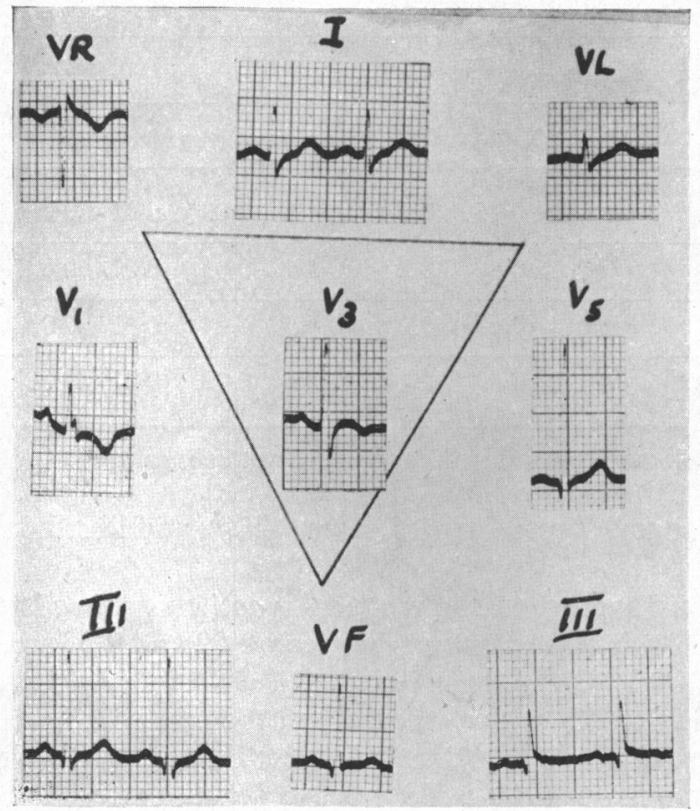

FIG. 4.-Normal heart from patient, aged $2 \frac{1}{2}$ years. Right axis deviation. Vertical heart. $\mathbf{R S R}^{\prime}$ in aVR, Rs in V1. T wave inverted in V1 and 3 .

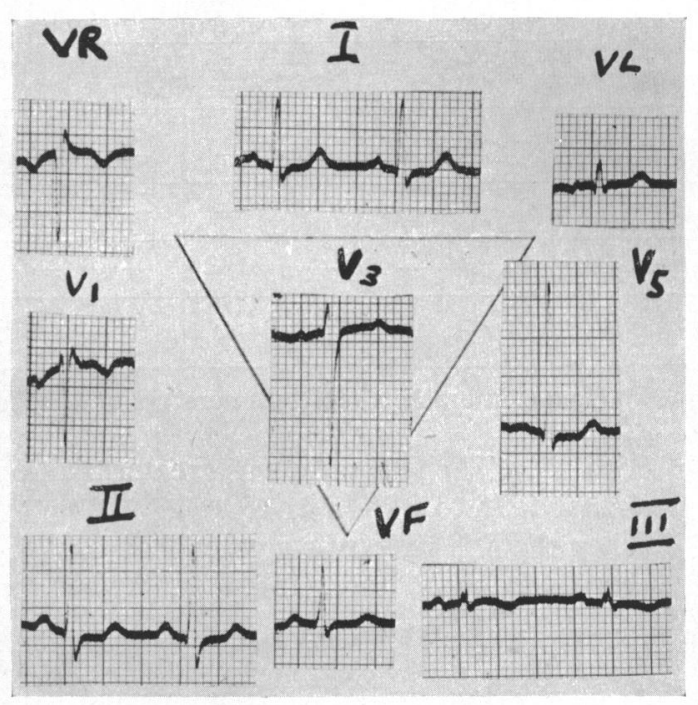

FIG. 5.-Normal heart from patient, aged 13 years. Qr in aVR, RSR' in V1. T wave inverted in V1. 
the $\mathrm{R} / \mathrm{S}$ ratio in $\mathrm{V} 1$ was greater than one, but was $0.02 \mathrm{sec}$. or less when the ratio was less than one. By contrast, the normal children all (with one exception) had times not exceeding $0.03 \mathrm{sec}$. irrespective of the $\mathrm{R} / \mathrm{S}$ ratio. In the abnormal series the 7 cases with $\mathrm{R} / \mathrm{S}$ in $\mathrm{V} 1$ equal to or less than one, all had prominent $R$ waves in lead $\operatorname{aVR}(Q / R$ ratio less than one, with a maximum of $0 \cdot 5$, in 6 , and monophasic $R$ in 1$)$. Fig. 12 shows the $Q / R$ ratio in aVR plotted against the ventricular activation time in V1 in 31 cases of right ventricular hypertrophy. In 6 cases with $R / S$ in V1 equal to or less than one, the activation time in V1 varies inversely with the size of $R$ in VR, and therefore directly with $Q / R$ in aVR. However, in 25 cases with $R / S$ in $V 1$ greater than one, there is no relation between the activation time in $\mathrm{V} 1$ and the $Q / R$ ratio in $\mathrm{aVR}$.

TABLE IV

R/S Ratios and Ventricular Activation Times in Lead V5

\begin{tabular}{|c|c|c|c|c|c|c|c|c|c|c|c|c|c|c|}
\hline & \multirow[t]{2}{*}{$\begin{array}{l}\text { No. of } \\
\text { Cases }\end{array}$} & \multicolumn{3}{|c|}{$\mathrm{R} / \mathrm{S}$ ratio } & \multicolumn{3}{|c|}{$\begin{array}{l}\text { Ventricular } \\
\text { activation } \\
\text { time/sec. }\end{array}$} & \multirow[t]{2}{*}{$\begin{array}{l}\text { No. of } \\
\text { Cases }\end{array}$} & \multicolumn{3}{|c|}{$\mathbf{R} / \mathbf{S}$ ratio } & \multicolumn{3}{|c|}{$\begin{array}{c}\text { Ventricular } \\
\text { activation } \\
\text { time/sec. }\end{array}$} \\
\hline & & Max. & Min. & Ave. & Max. & Min. & Ave. & & Max. & Min. & Ave. & Max. & Min. & Ave. \\
\hline & \multicolumn{14}{|c|}{$\mathbf{R} / \mathbf{S}$ ratio greater than 1} \\
\hline & \multicolumn{7}{|c|}{ Normals (52 cases) } & \multicolumn{7}{|c|}{ Right Ventricular Hypertrophy (15 cases) } \\
\hline Group I & $6(+3)$ & 12 & $2 \cdot 3$ & 3.9 & 0.04 & 0.02 & 0.03 & 1 & - & - & $4 \cdot 7$ & - & - & 0.03 \\
\hline Group II & $8(+1)$ & 17 & $2 \cdot 5$ & $6 \cdot 7$ & 0.04 & 0.02 & 0.03 & $7(+1)$ & $5 \cdot 3$ & $1 \cdot 2$ & $2 \cdot 6$ & 0.05 & 0.01 & 0.03 \\
\hline Group III & $14(+4)$ & 19 & 2 & $7 \cdot 1$ & 0.04 & 0.02 & 0.03 & $4(+1)$ & $1 \cdot 8$ & 1.4 & $1 \cdot 7$ & 0.04 & 0.02 & 0.025 \\
\hline \multirow[t]{3}{*}{ Group IV } & $12(+4)$ & 40 & 4 & 15 & 0.04 & 0.02 & 0.03 & (1) & - & - & - & - & - & 0.06 \\
\hline & \multicolumn{14}{|c|}{$\mathrm{R} / \mathrm{S}$ ratio less than 1} \\
\hline & \multicolumn{7}{|c|}{ Normals ( 1 case) } & \multicolumn{7}{|c|}{ Right Ventricular Hypertrophy (21 cases) } \\
\hline Group I & 0 & - & 一 & - & - & - & - & 5 & 0.75 & $0 \cdot 1$ & 0.47 & 0.03 & 0.01 & 0.026 \\
\hline Group II & 0 & - & - & - & - & - & - & 7 & 0.8 & 0.2 & 0.59 & 0.03 & 0.02 & 0.021 \\
\hline Group III & 1 & - & - & 0.42 & - & - & 0.03 & 5 & 0.68 & 0.29 & 0.47 & 0.04 & 0.02 & 0.024 \\
\hline Group IV & 0 & - & - & - & - & - & - & 4 & 0.43 & $0 \cdot 17$ & 0.36 & 0.02 & 0.01 & 0.017 \\
\hline
\end{tabular}

* Figures in brackets represent numbers of cases in which amplitude of deflection could not be measured.

Lead V5. The R/S ratio was greater than one (range 4.7 to $1 \cdot 2$ ) in 15 cases $(42 \%)$, and less than one (range 0.75 to $0 \cdot 1)$ in $21(58 \%)$.

When the $\mathrm{R} / \mathrm{S}$ ratio was greater than one, the group average of the ventricular activation time lay between 0.02 and $0.06 \mathrm{sec}$. (Fig. 8), and when the ratio was less than one, between 0.02 and $0.03 \mathrm{sec}$. (Fig. 10 and Table IV).

Ratio $R / S$ in $V 5$ divided by ratio $R / S$ in $V 1(R / S V 5 / R S V 1)$ was calculated and the maximum was 2.5 and the minimum 0.02 . The averages for each group were: Group I, $0.3 ;$ II, $1 \cdot 1$; III, 0.5 ; IV, $0 \cdot 1$. Although the age group averages were much lower than in the normal series, there was a wide scatter of individual ratios.

The $T$ waves. In lead V1 the $T$ wave was upright in 13 cases, biphasic in 5 , flat in 1 , and inverted in 17. In V5 it was upright in all except 1 case in Group II. In aVR the T wave was inverted in 


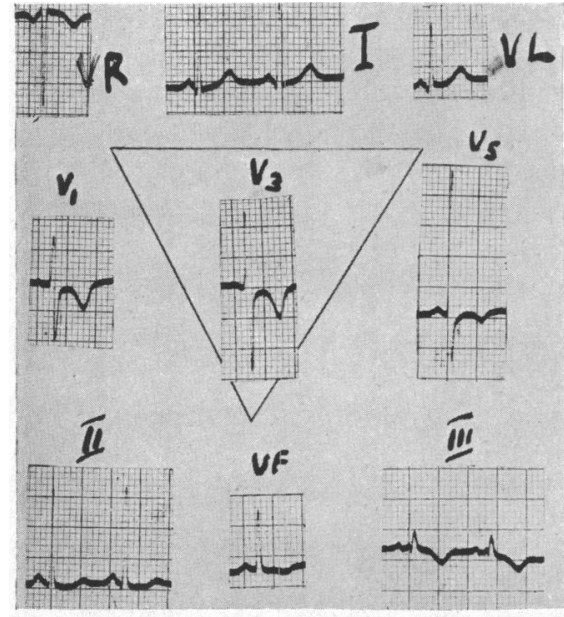

Fig. 6.-Normal heart. Age 5 years. rS in aVR, RS in V1. T wave inverted in $\mathrm{V} 1,3$, and 5 .

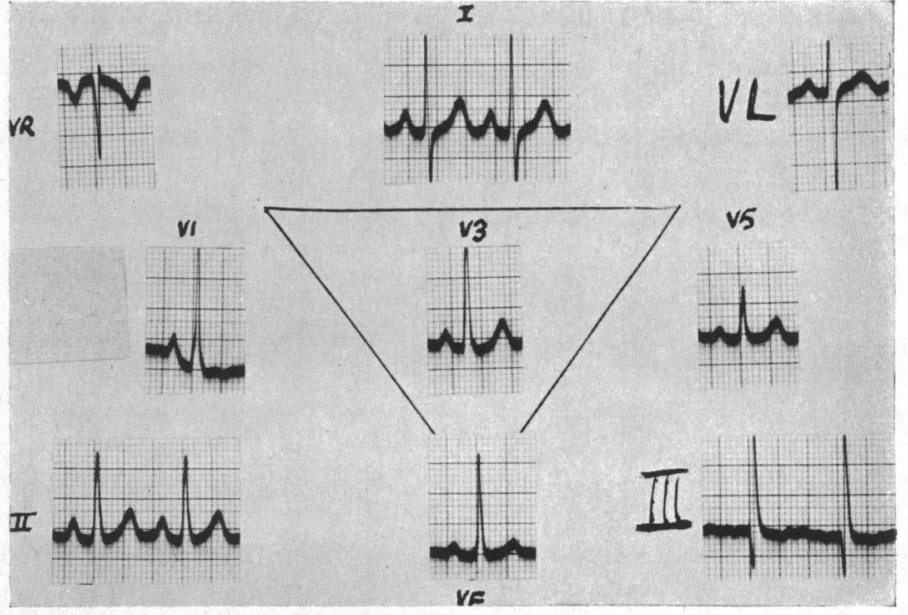

Fig. 7.-Right ventricular hypertrophy. Age 6 years. Right axis deviation, $\mathbf{Q r}$ in aVR. Monophasic $\mathbf{R}$ wave in præcordial leads. S-T segment depression and flat $T$ wave in V1. T wave upright in V3 and 5.

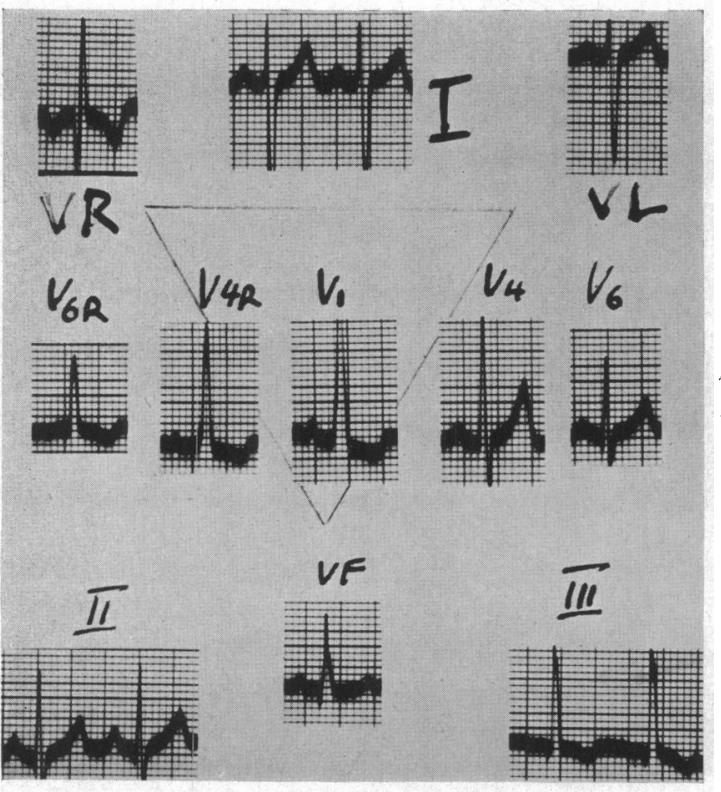

FIG. 8.-Right ventricular hypertrophy. Age $4 \frac{1}{2}$ years. Right axis deviation, $q R$ in aVR. V6R, V4R, and $V 1$ show monophasic $R$ waves. Rs in V4. Left ventricular $q$ in V6. $T$ wave inverted in V6R to $\mathrm{V} 1$.

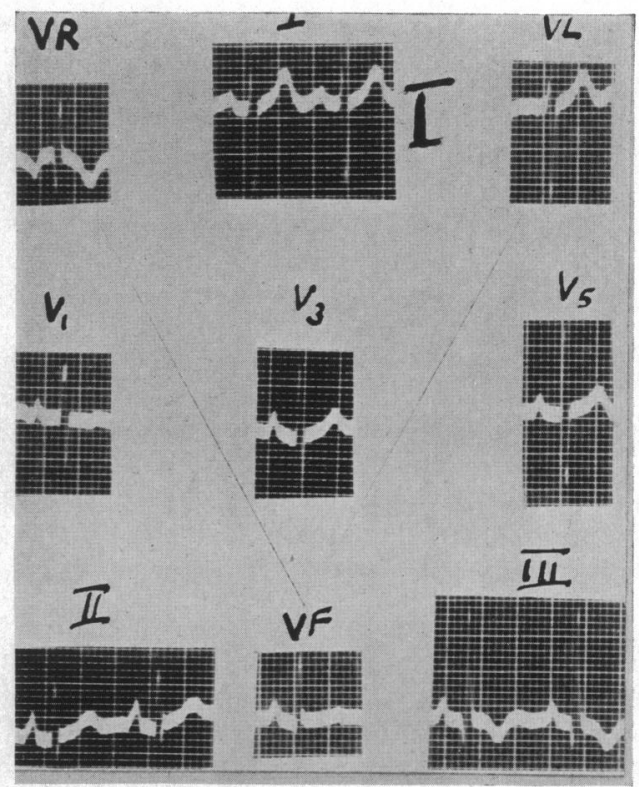

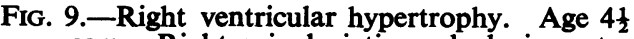
years. Right axis deviation, clockwise rotation, $\mathrm{qR}$ in aVR, RS in V1. T wave upright in V1 to 5 . 
every case, in aVL it was inverted in 3 , flat in 3 , biphasic in 2 , and upright in 28 , while in aVF it was inverted in 4, flat in 1, and upright in 31 cases. Age did not exert any influence.

Pracordial Leads to the Right of the Sternum. These were performed in 13 cases. In V4R or V3R 8 cases showed a qR pattern, 3 a monophasic tall $R$ wave, and 2 an RSR' with tall $R$ wave. The $Q / R$ ratios ranged from 0.02 to 0.4 (Fig. 8). Of the cases with $R / S$ in $V 1$ less than one, right sternal leads were obtained in one, in which the $Q / R$ ratio in $V 4 R$ was 0.03 . Of the 2 cases with $R / S$ in V1 equal to one, 1 had right sternal exploration which showed a $Q / R$ ratio of 0.03 in V5R (Fig. 11). In 2 cases only was the $T$ wave upright in V3R or V4R.

The ventricular activation time varied from 0.08 to $0.03 \mathrm{sec}$. It was $0.04 \mathrm{sec}$. in V4R and in V5R respectively in the two cases with $R / S$ in V1 less than one and equal to one.

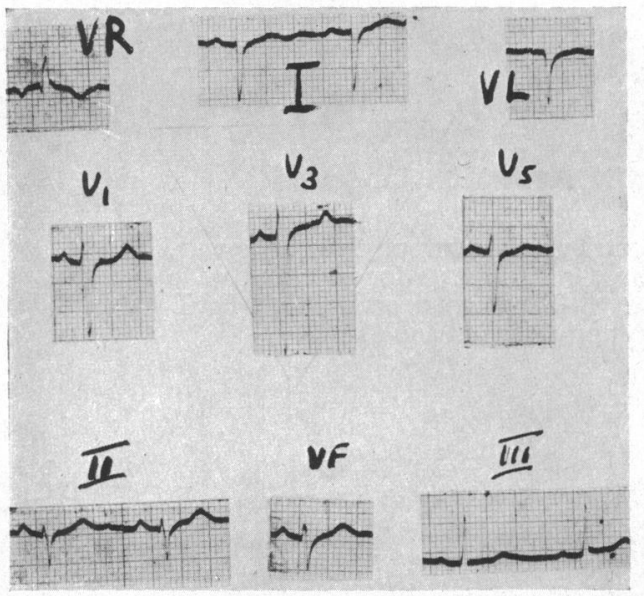

FIG. 10.-Right ventricular hypertrophy. Age 12. Right axis deviation, clockwise rotation, $\mathrm{qR}$ in aVR, $\mathrm{rS}$ in V1. Præcordial $\mathrm{T}$ waves upright.

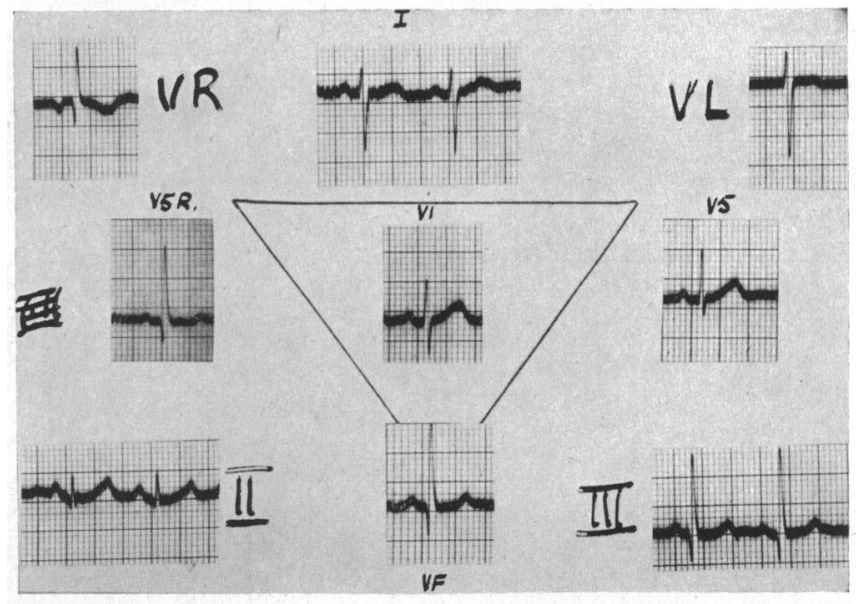

FIG. 11.-Right ventricular hypertrophy. Age 5. Right axis deviation, $q R$ in aVR, $q R$ in V5R, RS in V1. Rs in V5. Præcordial T waves upright.

\section{Discussion}

The results in the normal subjects are in general agreement with those of Switzer and Besoan (1950), although these workers did not measure $Q / R$ and $R / S$ ratios. Kuskin and Brockman (1950) studied the præcordial $\mathrm{T}$ waves in 321 normal infants and children and obtained results similar to those in this series. Battro and Mendy (1946) showed that in children from birth to two years the $R$ wave was frequently larger than the $S$ in lead V1. Schaffer et al. (1950) examined 50 normal infants, aged 1 to 6 days, and found appearances suggesting right ventricular hypertrophy (large $R$ in V6R, sternal lead, and aVR; marked clockwise rotation). They did not measure activation time, but in one cardiogram illustrated it was approximately $0.04 \mathrm{sec}$. in the three leads mentioned. Sokolow and Lyon (1949) studied children and adults with right ventricular hypertrophy and compared them with normal controls who were, however, mostly adults. They found that in normal children under the age of 5 years the $R / S$ ratio in V1 might be as much as 4 , but did not exceed one in persons above this age. The ratio RS in V5/RS in V1 was never less than $0 \cdot 4$, the average being 32. The same workers found the maximum ventricular activation time in V1 to be $0.03 \mathrm{sec}$., as was noted in this series (with the exception of one subject with an RSR'). Tudbury and Atkinson (1950) in a study of 100 normal infants and children found RSR' M-shaped complexes in V3R and V1. Myers et al. (1948) suggested that the $R$ wave in aVR should not exceed $5 \mathrm{~mm}$. in normal persons and found it greater than $5 \mathrm{~mm}$. in 23 per cent of a series of 40 cases of right ventricular hypertrophy. However, little has been written about the right arm lead ventricular complex in normal children, although a qR pattern is usual in newborn infants (Schaffer, 1950). 


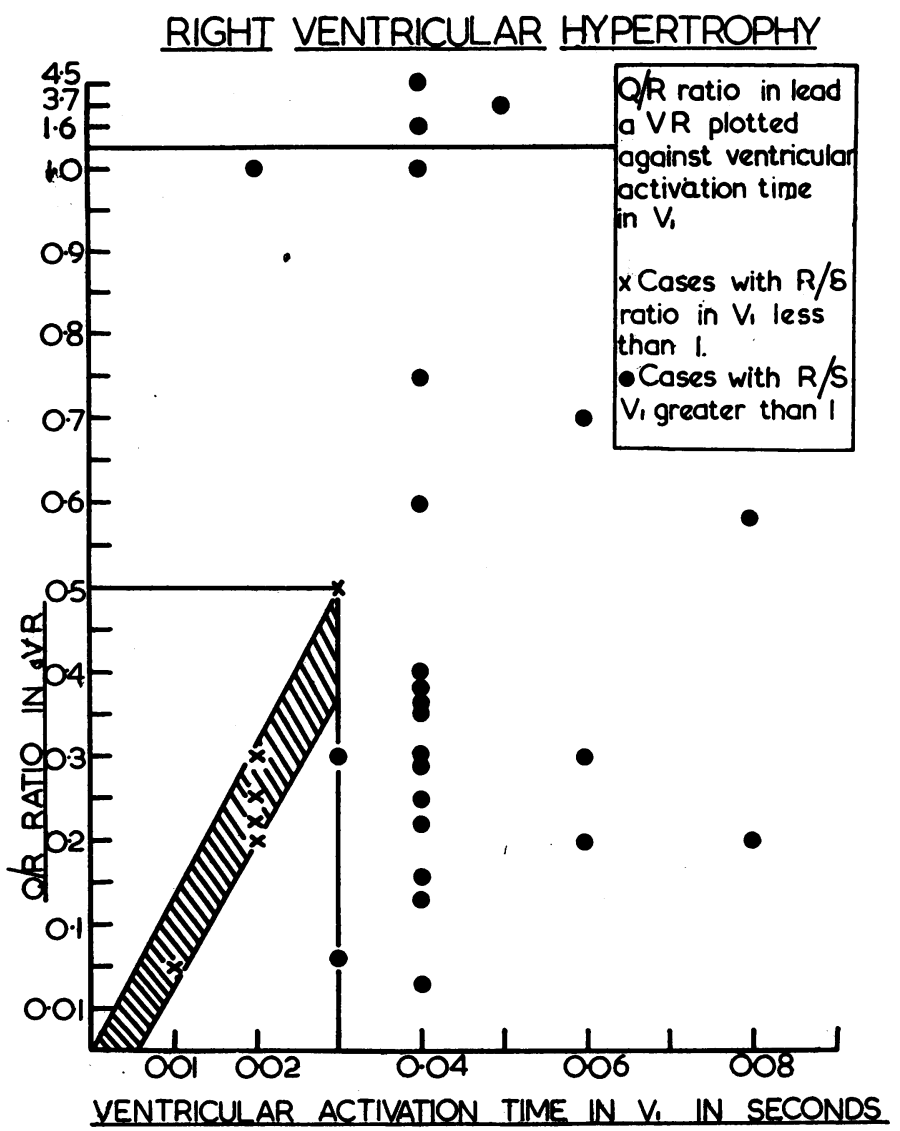

Fig. 12.-The $Q / R$ ratio in aVR plotted against the ventricular activation time in $\mathrm{V} 1$ in 31 cases of right ventricular hypertrophy.

The electrocardiographic appearances of right ventricular hypertrophy have been well described by Myers (1948) and by Sokolow and Lyon (1949). The former workers established the following criteria in a study of $\mathbf{4 0}$ adult cases.

(1) Reversal of ratio of $R$ and $S$ waves in V1 and V6, R larger than $S$ in V1, $S$ larger than $R$ in V6.

(2) Ventricular activation time 0.03 to 0.05 sec. in V1 and longer than in V5 or V6.

(3) Tendency to small q in V1.

(4) Tendency to inverted T wave in V1 and upright T in V6.

In one patient in Myers' series signs of right ventricular hypertrophy were present in V3R but not in V1 or V2. In 6 cases V1 was normal but aVR showed a tall $R$ (four to ten times the amplitude of the $Q$ wave) and an abnormally large $S$ in V6. In these 6 cases the changes were considered to be presumptive but not conclusive evidence of right ventricular hypertrophy, and tracings of 2 cases are shown which were found to have normal hearts at necropsy, in which the $Q / R$ ratio in aVR is approximately one. However, in Myers' Cases 12,13,19, and 20, where the $R$ wave in aVR is at least four times greater than the $Q$ wave and in one instance is monophasic, right ventricular hypertrophy was confirmed at necropsy, while in 23 of their cases of right ventricular hypertrophy $R$ in aVR was $5 \mathrm{~mm}$. or more. These investigators point out that backward rotation of the apex may result in an $R$ wave greater than the $Q$ in aVR, and Goldberger (1949) considered that $q R$ in 
aVR was due to extreme clockwise rotation, and might theoretically occur even in normal people, although he had never seen it.

Schack et al. (1950) in an analysis of the cardiograms of 100 normal adults found the ratio of the positive to negative waves ( $R / Q$ ratio) in aVR did not exceed 0.5 . In 27 adults with right ventricular hypertrophy the $R / Q$ ratio in $\mathrm{aVR}$ varied from 0.2 to 6 . These workers considered that an $R$ wave in aVR greater than $4 \mathrm{~mm}$. in adults and $5 \mathrm{~mm}$. in children over the age of two years constitutes one of the criteria of right ventricular hypertrophy.

Sokolow and Lyon (1949) in a study of 60 cases of right ventricular hypertrophy (24 of which were children) found the R/S ratio in V5 and V6 to be one or less in 19 cases, and the R/S ratio in V1 to be greater than one in 43 . RS in V5/RS in V1 was less than 0.4 in 15 cases. Unipolar præcordial leads in normal infants were characterized by a greater R/S ratio in V1 and V2 (up to 4) than seen in older persons, but did not show the delayed intrinsicoid deflection in V1 and V2 seen in right ventricular hypertrophy. Their youngest patient with right ventricular hypertrophy was one month old, but the ages of the normal infants are not given. As has already been mentioned, analysis of the cardiograms of one of Schaffer's (1950) normal two- to three-day-old infants reveals an activation time of $0.04 \mathrm{sec}$. in right præcordial and sternal leads. Sokolow and Lyon did not, however, consider the right arm lead to be of much value in the diagnosis of right ventricular hypertrophy.

The results of the present investigation show that the ventricular pattern in normal children over the age of one year may show wide variations that in certain instances resemble right ventricular hypertrophy. An R/S ratio of more than one in lead V1 occurred in 8 cases, all under the age of 8 years.

The appearances in Fig. 2 and 4 of an Rs complex in V1, with inversion of the T wave in V1 and V3 resemble the changes of right ventricular hypertrophy. In both these subjects, however, the ventricular activation time in V1 is less than $0.03 \mathrm{sec}$., and the negative deflection in aVR is much greater than the positive. These tracings may be contrasted with the appearances in Fig. 7 (right ventricular hypertrophy). In this case the ventricular activation time in V1 exceeds $0.03 \mathrm{sec}$., although the $Q / R$ ratio in aVR is 4 . Conversely Fig. 10 and 11 illustrate that RS or rS patterns and normal activation times, with upright $\mathrm{T}$ waves may occur in $\mathrm{V} 1$ in children with right ventricular hypertrophy. In these cases (and in others not illustrated) the R wave in aVR greatly exceeds the $\mathrm{q}$ wave, a finding that is never present in a normal subject. $\mathrm{T}$ wave inversion in the præcordal leads is of no value in the diagnosis of right ventricular hypertrophy, while slurring of the QRS in lead V1 occurs in normal children, as illustrated by Fig. 2.

The findings in this series suggest that the important signs of right ventricular hypertrophy are a $R / S$ ratio of greater than one with ventricular activation time greater than $0.03 \mathrm{sec}$. in lead V1, and a $\mathrm{Q} / \mathrm{R}$ ratio of less than one in lead aVR (Fig. 8). Cases of right ventricular hypertrophy may show only one or other of these two signs, as illustrated by Fig. 7 and 10. But in none of the cases of right ventricular hypertrophy presented have both these signs been absent. Fig. 11 also shows a large $R$ wave and ventricular activation time of more than $0.03 \mathrm{sec}$. in V5R.

$A Q / R$ ratio of less than one in aVR is a useful sign of right ventricular hypertrophy, especially when $\mathrm{V} 1$ is normal, although a ratio of more than one does not exclude it. In children with $Q / R$ in aVR greater than one, or with a predominantly negative deflection in this lead, an activation time of $0.06 \mathrm{sec}$. or more is suggestive of right ventricular hypertrophy (Fig. 7).

Clockwise rotation of the heart on its vertical axis or backward rotation of the apex can produce an $R$ wave larger than the Q in aVR (Myers et al., 1948; Goldberger, 1949), but the evidence suggests that such a degree of rotation does not occur in the absence of right ventricular hypertrophy in children over the age of one year. In other respects the findings agree with those of Sokolow and Lyon (1949), except that they considered the ratio RS in V5/RS in V1 to be more helpful than the present results suggest. The presence of a large $R$ wave in leads V3R and V4R with activation times exceeding $0.03 \mathrm{sec}$. in all the cases of right ventricular hypertrophy in which these leads were recorded indicates that this pattern is an important diagnostic aid.

The results of the present investigation do not indicate the mechanism of the electrocardio- 
graphic changes of right ventricular hypertrophy. In the extreme example, the appearances suggest that the heart is electrically " back to front" and that right præcordial and sternal leads face the left ventricle, and vice versa. Lead aVR also appears to face the left ventricle, so that possibly the extreme degree of clockwise rotation rather than the increased thickness of the ventricular muscle is responsible for the characteristic complexes. This suggestion is supported by the work of MacGregor (1950) who found that direct right ventricular epicardial leads in cases of right ventricular hypertrophy showed an $\mathrm{rS}$ pattern, although he was not able to explore the right ventricle fully. The ventricular activation time in these leads lay within the normal range. In the present series the average activation time in V5 in each age group in cases of right ventricular hypertrophy was usually $0.03 \mathrm{sec}$. or less, but was not significantly shorter than in the normal subjects. The $q R$ in aVR and large $R$ in aVR are rotational phenomena, and their frequent appearance in right ventricular hypertrophy is further evidence of marked clockwise rotation and/or backward rotation of the apex, so that left ventricular potentials are reflected to the right arm. On the other hand, examination of the appearances in Fig. 7 and 8 in which rS complexes do not appear in any præcordial lead but are seen in aVL suggests that increase in thickness of the ventricular muscle as well as rotation of the heart is responsible for the patterns. The significance of the combination of an $\mathrm{rS}$ or RS pattern with normal ventricular activation time in V1, with a $\mathrm{qR}$ complex in aVR, seen in 7 cases and illustrated in Fig. 9, 10, and 11 is difficult to assess. Possibly in these children V1 does not face the hypertrophied portion of right ventricular muscle, while aVR faces left ventricular muscle as a result of clockwise rotation or apical tilting. Fig. 10 shows considerable clockwise rotation, while in Fig. 11 there is little of this rotation but probably considerable backward apical tilt producing $\mathrm{qR}$ complexes in aVR and V5R.

It is clear that cardiac rotation cannot be solely responsible for the appearances in right ventricular hypertrophy, and the part it plays will await more detailed studies involving extensive epicardial exploration and the new techniques of spatial vectorcardiography.

\section{SUMMARY}

Standard and unipolar lead electrocardiograms recorded from 53 normal children between the ages of 1 and 15 years have been compared with tracings taken from 36 children of similar ages with right ventricular hypertrophy.

In the normal subjects the usual finding in lead V1 was an $\mathrm{rS}$ pattern with an R/S ratio less than one, but in 15 per cent this ratio was greater than one. The ventricular activation time in V1 never exceeded $0.03 \mathrm{sec}$. except in one case showing an RSR' complex. In lead aVR the positive deflećtion was never greater than the negative and the activation time did not exceed $0.06 \mathrm{sec}$.

In right ventricular hypertrophy the following patterns were seen in $V 1$ : $q R$ with $Q / R$ ratio less than one; Rs with $\mathrm{R} / \mathrm{S}$ ratio greater than one (both with activation times exceeding $0.03 \mathrm{sec}$.); and $\mathrm{RS}$ or $\mathrm{rS}$ with $\mathrm{R} / \mathrm{S}$ ratio equal to one or less than one, and activation times of $0.03 \mathrm{sec}$. or less.

In lead aVR the positive deflection was greater than the negative in 83 per cent of cases, including 5 with $\mathrm{rS}$ and 2 with RS patterns in V1. A Q/R ratio less than one in lead aVR, although in itself merely a sign of extreme clockwise rotation or backward tilting of the heart, is a highly suggestive indirect sign of right ventricular hypertrophy, although its absence does not exclude the diagnosis. It is a particularly important sign in cases in which V1 is normal. A ventricular activation time of more than $0.06 \mathrm{sec}$. in aVR did not occur in any normal subject but was seen in cases of right ventricular hypertrophy in which the $Q / R$ ratio in this lead exceeded one.

In 13 cases $(30 \%)$ in the right ventricular hypertrophy series right sternal leads V5R to V3R were recorded and showed a larger positive than negative deflection and activation times of $0.03 \mathrm{sec}$. or more.

Inversion of the $\mathrm{T}$ wave in præcordial leads $\mathrm{V} 1$ to $\mathrm{V} 3$ was not found to be a valuable sign of right ventricular hypertrophy, since it was often present in normals. Conversely, the $T$ wave was often upright in the same leads in right ventricular hypertrophy. 
The possible mechanism of the changes seen in right ventricular hypertrophy are briefly discussed and it is suggested that in certain cases extreme clockwise rotation may play a part in the production of the qR complex in V1 and aVR by causing the left ventricle to face these leads, but that other factors certainly contribute.

I wish to thank Professor E. J. Wayne for his assistance and encouragement, Professor R. S. Illingsworth and Dr. T. Colver for their co-operation, and Mr. A. G. Barritt for technical help. Professor J. McMichael, Dr. Maurice Campbell, Dr. David Lewes, and Dr. Alastair Macgregor kindly gave valuable advice on the preparation of the paper.

\section{REFERENCES}

Battro, A., and Mendy, J. C. (1946). Arch. intern. Med., 78, 31.

Goldberger, E. (1944). Amer. Heart J., 28, 621.

(1947). Unipolar Lead Electrocardiography. Henry Kimpton, London.

(1949). Amer. J. med., 7, 736.

Kuskin, L., and Brockman, L. (1949). Amer. J. med. Sci., 218, 65.

MacGregor, M. (1950). Brit. Heart J., 12, 351.

Myers, G. B. (1950). Amer. Heart J., 39, 637.

Klein, H. A., and Stofer, B. E. (1948). Amer. Heart J., 35, 1.

Schaffer, A. J., Bernstein, J., Norina, A. J., Barenberg, P. L., and Stillman, N. (1950). Amer. Heart J., $39,588$.

Schack, J. A., Rosenbaum, R. H., and Katz, L. N. (1950). Amer. Heart J., 40, 696.

Sokolow, M., and Lyon, T. P. (1949). Amer. Heart J., 38, 273.

, and Edgar, A. L. (1950). Amer. Heart J., 40, 232.

Switzer, J. L., and Besoan, M. (1950). Arch. intern. Med., 79, 449.

Tudbury, P. B., and Atkinson, D. W. (1950). J. Padiatrics., 36, 466.

Wilson, F. N., Rosenbaum, F. F., and Johnston, F. D. (1947). Advances in Internal Medicine, Vol. II. New York. 